\title{
The Nitric 0xide/cGMP Pathway Tunes the Thermosensitivity of Swimming Motor Patterns in Xenopus laevis Tadpoles
}

\author{
R. Meldrum Robertson ${ }^{1,2}$ and Keith T. Sillar ${ }^{2}$ \\ ${ }^{1}$ Department of Biology, Queen's University, Kingston, Ontario K7L 3N6, Canada, and ${ }^{2}$ School of Biology, University of St. Andrews, Fife KY16 9TS, \\ United Kingdom
}

\begin{abstract}
We investigated the role of the nitric oxide (NO)/cGMP pathway in setting thresholds for failure and recovery during hyperthermic stress of the swimming central pattern generator of immobilized Xenopus tadpoles (stage 42). We recorded swimming motor patterns induced by tail skin stimulation (TS) (1 ms current pulse) or by bath application of $50 \mu \mathrm{M}$ NMDA. Swimming rhythm frequency increased in a linear manner with increasing temperature. In the presence of the NO donor $S$-nitroso- $N$-acetylpenicillamine (SNAP), recovery from hyperthermic failure was greatly slowed, often taking longer than the duration of the experiment. Pharmacological activation of the NO/cGMP pathway using SNAP or 8-bromo-cGMP (1) decreased the duration of TS-evoked swim episodes; (2) decreased the temperature threshold for hyperthermic circuit failure; (3) decreased the temperature at which the circuit recovered; and (4) increased the time taken to recover. Pharmacological inhibition of the NO/cGMP pathway using the NO scavenger CPTIO, the nitric oxide synthase (NOS) inhibitor L-NAME or the guanylyl cyclase inhibitor ODQ $(1 \mathrm{H}$-[1,2,4] oxadiazolo[4,3-a]quinoxalin-1-one) had the opposite effects. NMDA rhythms were more resistant to hyperthermic failure than TS-evoked swim episodes, but the effects of SNAP on the temperature sensitivity of swimming evoked by NMDA were similar to those on TS-evoked swimming, suggesting that drug effects occur on central patterngenerating networks rather than sensory pathways. We conclude that the NO/cGMP pathway is involved in setting the threshold temperatures for hyperthermic failure and subsequent recovery of fictive swimming in tadpoles, and we suggest that this is part of a variable response to prevent overexcitation during abiotic stress under different environmental conditions.
\end{abstract}

\section{Introduction}

Central neural circuits are vulnerable to extreme high temperatures whether this results from intrinsic mechanisms, such as fever, or from increases in ambient temperature that the organism cannot adequately compensate for either physiologically or behaviorally. Protective mechanisms targeting vital motor activities such as ventilation, predator evasion, and locomotion out of regions of high temperature are clearly selectively advantageous (Robertson, 2004). Long-term processes of acclimation (Johnston and Temple, 2002) can modify neuronal properties and change optimal temperature ranges (Behan-Martin et al., 1993). More rapid processes requiring protein synthesis can be activated by heat shock pretreatments (Robertson et al., 1996; Kelty et al., 2002; Armstrong et al., 2006; Rodgers et al., 2007), and in larval Drosophila the stress protein HSP70 has been shown to have a role in protecting locomotion (Xiao et al., 2007), and calcium dynamics at the neuromuscular junction (Klose et al., 2008), from hyperthermia. Recently, the nitric oxide (NO)/

\footnotetext{
Received Aug. 6, 2009; revised Sept. 10, 2009; accepted Sept. 11, 2009.

This work was supported by the Biotechnology and Biological Sciences Research Council (United Kingdom) and the Natural Sciences and Engineering Research Council (Canada). We also thank Tom Money and Gary Armstrong for their comments on this manuscript.

Correspondence should be addressed to R. Meldrum Robertson, 3118 Biosciences Complex, Queen's University, Kingston, ON K7L 3N6, Canada. E-mail: robertrm@queensu.ca.

DOI:10.1523/JNEUROSCI.3841-09.2009

Copyright $\odot 2009$ Society for Neuroscience $\quad$ 0270-6474/09/2913945-07\$15.00/0
}

cGMP/protein kinase G pathway has been implicated in rapid adaptation of the temperature sensitivity of motor circuits in insects (Dawson-Scully et al., 2007), but it is not known whether similar mechanisms are operational in vertebrates. The swimming central pattern generator (CPG) in the spinal cord of Xenopus tadpoles has a well described modulation by NO (McLean and Sillar, 2002, 2004), and here we demonstrate that the NO/ cGMP pathway tunes the thermosensitivity of this system.

The CPG controlling tadpole swimming provides an excellent model system for investigations of the operation and modulation of neuronal circuits in the vertebrate spinal cord (Arshavsky et al., 1993; Dale and Kuenzi, 1997; Sillar et al., 2008). The endogenous release of NO from brainstem neurons has been described as acting like a "brake" on swimming. It has two major effects on the swim motor pattern: a decrease in the duration of swim episodes elicited by stimulation of the skin and an increase in the period of the swim cycle (McLean and Sillar, 2000). NO achieves this by facilitating both glycinergic inhibition (increasing midcycle inhibition amplitude and hence cycle period) and GABAergic inhibition (decreasing episode duration) (McLean and Sillar, 2002). The facilitatory effect of NO on glycinergic inhibition is mediated in a metamodulatory manner via the descending noradrenergic neuromodulatory pathway (McLean and Sillar, 2004). Thus, the duration and intensity of swimming activity is under a continuous neuromodulatory control via NO, and the underlying mech- 
anisms are well understood, although the environmental or behavioral contexts for this control are unknown.

Variation in ambient temperature has marked effects on swimming vigor (maximum velocity and distance traveled) of Xenopus tadpoles, and the system can be acclimated for optimal performance in different environments (Wilson et al., 2000). At the level of the spinal cord, increases in temperature decrease the cycle period of fictive swim motor patterns and decrease the duration of tail-stimulated swim episodes, until a critical temperature at which regular swimming cannot be evoked but spontaneous bouts of escape activity occur (Sillar and Robertson, 2009). In the present study, we used standard pharmacological treatments to test the hypothesis that the NO/cGMP pathway modulates these measures of thermosensitivity of the swimming CPG. Our results indicate that the level of activation of the NO/cGMP pathway determines the response of the system to temperature changes in ways that would be predicted to reduce energy demand at high temperatures.

\section{Materials and Methods}

Animals. Xenopus laevis larvae were obtained from a breeding colony maintained in the School of Biology at the University of St. Andrews and staged according to features defined by Nieuwkoop and Faber (1956). Stage 42 larvae were used for all experiments, which were conducted in accordance with the UK 1986 Animals (Scientific Procedures) Act. To ensure a steady supply of experimental animals, frogs were bred twice a week, and the progeny were reared in enamel trays under three temperature conditions: at room temperature $\left(\sim 20^{\circ} \mathrm{C}\right)$, on a cooling surface $\left(\sim 17^{\circ} \mathrm{C}\right)$ to slow development, and on a warming pad $\left(\sim 23^{\circ} \mathrm{C}\right)$ to speed development.

Electrophysiology. Experimental tadpoles were immobilized in $10 \mu \mathrm{M} \alpha$-bungarotoxin for 30-40 min and then transferred to the $5 \mathrm{ml}$ recording chamber which was perfused $(\sim 5 \mathrm{ml} / \mathrm{min})$ with $100 \mathrm{ml}$ of recirculating saline (in mM: $115 \mathrm{NaCl}, 2.5 \mathrm{KCl}, 2.5 \mathrm{NaHCO}_{3}, 10$ HEPES, $1 \mathrm{MgCl}_{2}, 4 \mathrm{CaCl}_{2}, \mathrm{pH} 7.4$ with $\mathrm{NaOH}$ ). Using $\mathrm{KOH}$-sharpened tungsten needles, the flank skin was removed to uncover the lateral myotomes, and the animal was stabilized with the dorsal surface uppermost (Fig. 1A). Glass suction electrodes ( $\sim 50 \mu \mathrm{m}$ tip diameter $)$ were placed over the intermyotomal clefts to record from motoneurons in the ventral roots of the spinal cord. The three electrodes helped to stabilize the preparation and were used to characterize swimming rhythms. The recordings on the left side were most usually made from the fourth or fifth and 11th or 12th post-otic intermyotomal clefts, a separation of $\sim 1.5 \mathrm{~mm}$ (Fig. $1 \mathrm{~A}$ ). This enabled estimates of the propagation rate of information along the spinal cord during motor activity. Contralateral activity was recorded with an electrode positioned usually at the fifth to the eighth ventral root cleft. Swimming rhythms were elicited either by brief electrical stimulation of the tail [ $1 \mathrm{~ms}$ pulses normally delivered at $1.5 \times$ the threshold voltage, tail skin stimulation (TS) swimming] (Fig. $1 B$ ) or by bath application of 50 $\mu \mathrm{M}$ NMDA (NMDA swimming) (Fig. 1C) (Dale and Roberts, 1984).
Swim episode duration is influenced by the time since the previous swim, and thus a standard $8 \mathrm{~s}$ period was allowed to elapse at the end of one swim episode before the stimulus to start the next. This protocol likely did not avoid all habituation, but it standardized it to enable comparison between treatments and animals. Extracellularly recorded motor activity was amplified using a differential AC amplifier (A-M Systems; Model 1700), digitized using a Digidata 1322A data acquisition system (Molecular Devices) before viewing and storage using Axoscope 10.1 software (Molecular Devices). Data analysis was also performed using DataView v.6.1 (courtesy of W. J. Heitler, University of St. Andrews).

The temperature of the saline was increased using a heating element wrapped around a glass section in the inlet tubing and was monitored with a temperature probe $\left(0.1^{\circ} \mathrm{C}\right.$ resolution; VWR International) placed adjacent to the tip of the tail at the point where circulating saline entered the chamber. Repeatable temperature ramps from room temperature $\left(18-22^{\circ} \mathrm{C}\right)$ to $\sim 38^{\circ} \mathrm{C}$ over a 6 min period were obtained by turning on the heater. Turning it off allowed a passive, slower return to room temperature in $8-10 \mathrm{~min}$. The recovery period for swimming after turning off the heater had two components: temperature, which declined exponentially 
A

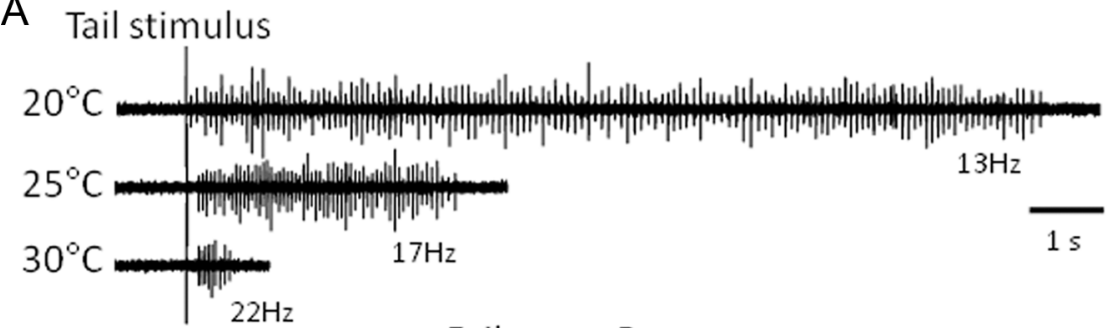

B Tail stimulation HW. Why H.M.

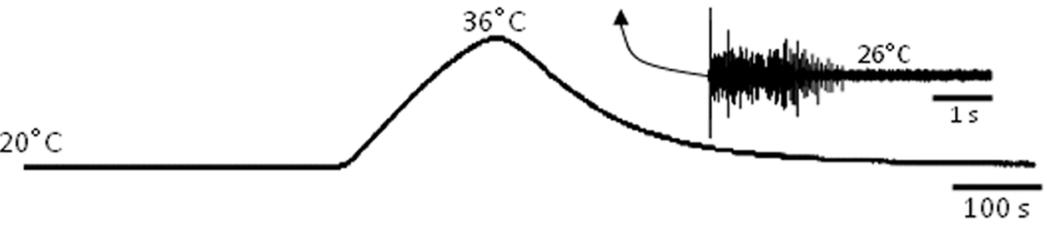

C $50 \mu \mathrm{MNMDA}$

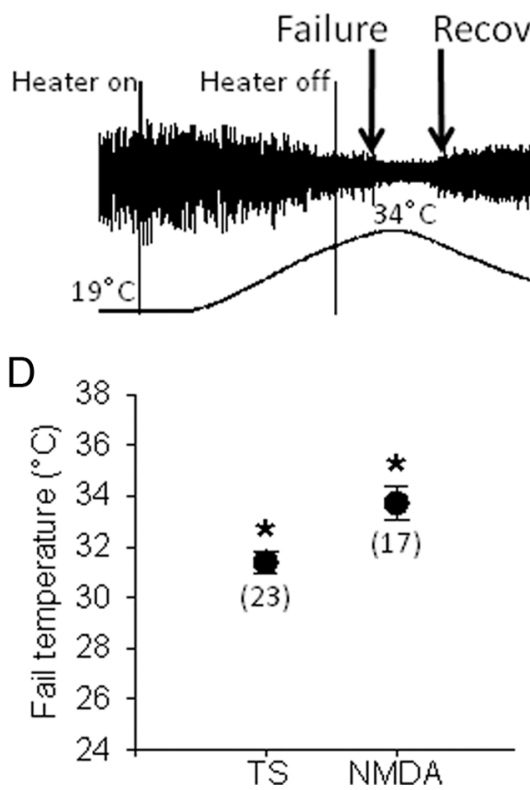

min
$\mathrm{E}$

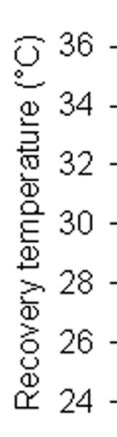

Figure 2. Temperature sensitivity of swimming motor patterns. A, Sample traces from one ventral root showing that increasing temperature increased swim frequency and reduced episode duration. Frequencies given are for the first 5 cycles in each sequence. Timing of the tail stimulus is indicated by the artifacts that are lined up in these separate recordings. $\boldsymbol{B}$, An increasing temperature ramp from 20 to $36^{\circ} \mathrm{C}$ caused the TS-evoked motor pattern to fail. Recovery was observed soon after the temperature was allowed to return toward room temperature. The inset shows the $2 \mathrm{~s}$ duration swim episode at time of circuit recovery (at $26^{\circ} \mathrm{C}$ ). $\mathrm{C}, \mathrm{An}$ increasing temperature ramp from 19 to $34^{\circ} \mathrm{C}$ caused the NMDA-evoked motor pattern to fail. Recovery occurred rapidly after the temperature started to return to room temperature. The timing of heater on and heater off is indicated by the electrical artifacts. The delay between these points and the subsequent change in temperature was due to the distance between the heater in the circulation system and the location of the temperature probe by the animal. D, NMDA-evoked motor patterns failed at higher temperatures than TS-evoked motor patterns. E, NMDA-evoked motor patterns recovered at higher temperatures than TS-evoked motor patterns. In $\boldsymbol{D}$ and $\boldsymbol{E}$, data points indicate means $\pm \mathrm{SE}$, and sample size is indicated parenthetically under the symbol. Asterisks indicate significant differences $(p<0.05)$

during the 8-10 min interval, and time. In the majority of cases, the swim motor pattern recovered within the period of temperature decline, but in some cases, when drug treatments impaired recovery, swimming returned after the temperature had returned to control levels.

Pharmacology. Drugs were added to the $100 \mathrm{ml}$ saline reservoir in sufficient quantities to make the final desired concentration. Unless otherwise indicated, chemicals were obtained from Sigma-Aldrich. We used NMDA $(50-100 \mu \mathrm{M})$ to activate fictive swimming motor patterns; $S$-nitroso- $N$-acetylpenicillamine (SNAP; $100-200 \mu \mathrm{m}$; supplied by Dr.
A. R. Butler, School of Chemistry, University of St. Andrews) as an NO donor; 8-bromo cyclic guanosine monophosphate (8-bromo-cGMP; $40 \mu \mathrm{M})$ a membrane-permeable cGMP analog and activator of protein kinase G; 2-[-4carboxyphenyl]-4,4,5,5-tetramethylimidazoline-1-oxyl-3-oxide potassium salt (CPTIO; $100 \mu \mathrm{M})$ as an NO scavenger; $N$-nitro-Larginine methyl ester (L-NAME; $1-5 \mathrm{~mm}$ ) to inhibit NO synthase; and $1 H$-[1,2,4] oxadiazolo[4,3-a]quinoxalin-1-one (ODQ; 10-20 $\mu \mathrm{M})$ to inhibit guanylyl cyclase. Drugs were dissolved in distilled water (NMDA, 8-bromocGMP, CPTIO, L-NAME) or $0.01 \%$ dimethyl sulfoxide (SNAP, ODQ) which has been shown not to exert vehicle-mediated effects on this preparation (McLean and Sillar, 2002). Drugs were allowed at least $15 \mathrm{~min}$ to exert their effects before applying the temperature ramp, with the exception of 8-bromo-cGMP which was allowed at least $40 \mathrm{~min}$.

Statistics. The results are based on recordings from 133 successful experiments. Graphs were prepared, and statistical comparisons were performed using Sigmaplot v.11.0 (Systat Software). Samples were tested for normality and equal variance, and the appropriate parametric or nonparametric tests were applied as follows: when the data were distributed normally and with equal variance, $t$ tests were used to compare two groups and ANOVAs followed by Holm-Sidak pairwise comparisons to determine where the differences lie among multiple groups. When the data were not normally distributed or failed the equal variance test, Mann-Whitney rank sum tests were used to compare two groups, and Kruskal-Wallis oneway ANOVAs on ranks followed by Dunn's pairwise comparisons to determine where the differences lie among multiple groups. Parameter values are presented as mean \pm SE. Significance was assessed with $p<0.05$.

\section{Results}

Swim motor pattern generation fails during hyperthermia

As described previously (Sillar and Robertson, 2009), during an increasing temperature ramp, swim cycle frequency (1/ cycle period) increased, and episode duration decreased (Fig. $2 \mathrm{~A}$ ) before reaching an upper temperature limit for pattern generator activity at which point TS-evoked swimming failed (Fig. 2B, down arrow; failure). Recovery occurred during the subsequent return to room temperature (Fig. 2B, down arrow; recovery). We found that continuous swimming, induced by superfusion of the preparation with $50 \mu \mathrm{M}$ NMDA, was similarly sensitive to temperature (Fig. $2 C)$, though it had higher temperature thresholds for failure and recovery (Fig. $2 \mathrm{D}, E$ ). Failure temperature was $31.4 \pm 0.4^{\circ} \mathrm{C}$ $($ mean $\pm \mathrm{SE} ; n=23)$ for TS swimming and $33.7 \pm 0.7^{\circ} \mathrm{C}(n=17)$ for NMDA swimming ( $p=0.004$; $t$ test), whereas recovery temperature was $26.5 \pm 0.5^{\circ} \mathrm{C}$ for TS swimming and $30.3 \pm 0.9^{\circ} \mathrm{C}$ for NMDA swimming ( $p=0.005$; Mann-Whitney rank sum test). The differences between failure and recovery temperatures were 
significant for both TS swimming $(p<$ 0.001 ; $t$ test $)$ and NMDA swimming ( $p=$ 0.003; Mann-Whitney rank sum test).

\section{NO hinders swim recovery after hyperthermic failure}

Under normal circumstances, the time taken for the swimming pattern generator to recover was between 3 and 5 min (TS swimming $=4.9 \pm 0.4 \mathrm{~min} ; \mathrm{NMDA}$ swimming $=3.5 \pm 0.5 \mathrm{~min} ; p=0.009$, $t$ test; data not shown). In the presence of the NO donor, SNAP $(100 \mu \mathrm{M})$, swimming motor patterns generally did not recover during the time course of the return to room temperature (recovery $>15 \mathrm{~min}$ ) whether they were elicited by TS (Fig. 3A) or NMDA (Fig. 3B). Nevertheless, of 12 preparations tested in the presence of SNAP (3 NMDA and 9 TS) only one (TS) did not recover within $35 \mathrm{~min}$, at which point the experiment was terminated. After recovery, parameters of the motor pattern in these preparations were not quantifiably different from those of recovered preparations not treated with SNAP.

The NO/cGMP pathway modulates the temperature sensitivity of swimming At high temperatures, the NMDA patterns appeared more irregular and harder to measure. Thus, to investigate the NO/cGMP pathway more completely, we measured the thermosensitivity of TS swimming in the presence of 8-bromo-cGMP and SNAP for pathway activation and CPTIO, L-NAME, and ODQ for pathway inhibition. The effects of 8-bromo-cGMP and ODQ on the swimming rhythm at room temperature have not previously been described. Parameters of the swimming rhythm were compared before and 10-20 min after bath application of the drugs. In within preparation comparisons, 8-bromo-cGMP reduced episode duration to $0.49 \pm 0.04(n=5)$ times its pretreatment value, whereas ODQ increased episode duration to $2.0 \pm 0.49(n=5)$ times the pretreatment value (see also Fig. $4 A i)$. These effects were significantly different from each other ( $p=0.008$; Mann-Whitney rank sum test). In these preparations, we found no consistent effect on swim cycle frequency or motor burst duration (data not shown) but attribute this to the inherent variability in these measures within and between different swim episodes at this stage of development and to low sample size.

Next, we tested NO/cGMP pathway-mediated effects on temperature dependence of swim motor patterns. The relationship between rhythm frequency and temperature is approximately linear with a $Q_{10}$ of $\sim 1.5$ (Sillar and Robertson, 2009). There were no overall differences in regression slopes (control value $=0.7$ $\mathrm{Hz} /{ }^{\circ} \mathrm{C}$ ) among the different treatment groups ( $p=0.7$; KruskalWallis one-way ANOVA) (Table 1), nor were there differences in the regression intercepts (control value $=-0.34 \mathrm{~Hz} ; p=0.7$; Kruskal-Wallis one-way ANOVA) (Table 1).

A
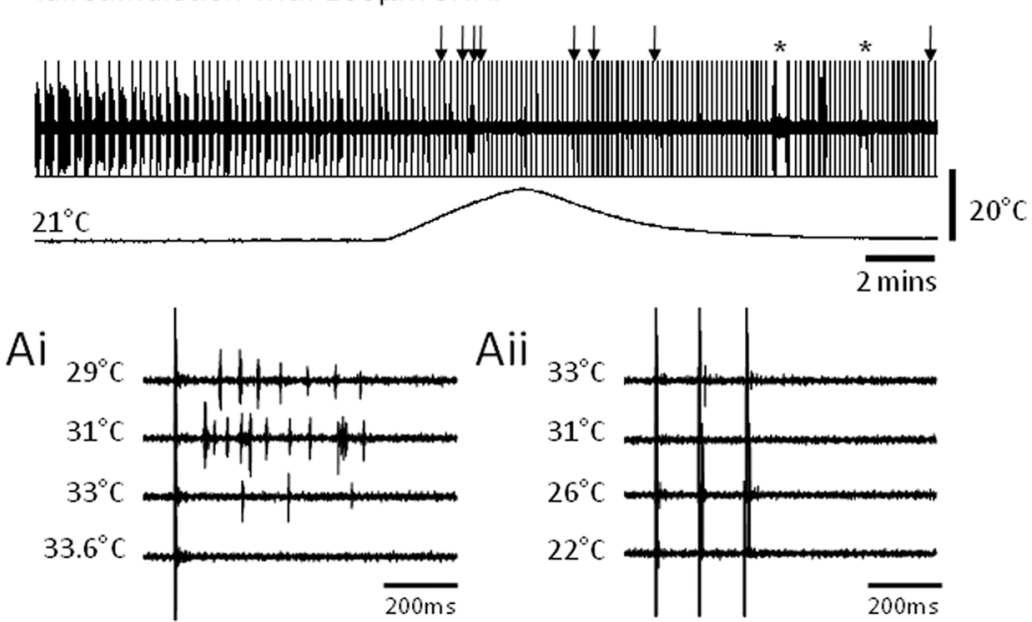

Figure 3. NO hinders motor pattern recovery from hyperthermic failure. $A$, Sample trace showing that in the presence of the NO donor SNAP $(50 \mu \mathrm{m})$ TS-evoked swim episodes do not recover during the $12 \mathrm{~min}$ after the point when the temperature starts to decrease. Arrows above the trace indicate episodes expanded in $\mathbf{A i}$ and $A i i$. Asterisks above the trace indicates artifacts and delays (first 4 arrows in $A$ ). At $29^{\circ} \mathrm{C}$, there is a short sequence of regular swimming activity. At $31^{\circ} \mathrm{C}$, the swimming rhythm appears 列 swity. B, Sample trace showing that in the presence of the NO donor SNAP $(50 \mu \mathrm{M})$, NMDA-evoked swimming motor in did not recover in the $13 \mathrm{~min}$ after the point when the temperature starts to decrease. The first two electrical artifacts are associated with the heater being turned on then off. The third artifact is of unknown origin but was likely caused by static discharge between the experimenter and the equipment.

We measured swim episode durations at room temperature, at $30^{\circ} \mathrm{C}$ on the increasing temperature ramp and at $30^{\circ} \mathrm{C}$ during recovery, on the decreasing temperature ramp. At room temperature, treatments that activated the NO/cGMP pathway led to shorter episode durations, whereas treatments that inhibited the pathway had longer episode durations (Fig. 4Ai). There was a significant effect of treatment ( $p=0.02$; Kruskal-Wallis oneway ANOVA) with a pairwise difference between the NO donor (SNAP) and the guanylyl cyclase inhibitor (ODQ) $(p<0.05$; Dunn's method). At higher temperatures before failure, this effect was exacerbated with no episodes recorded under 8-bromocGMP treatment (zero duration), whereas preparations with inhibitory treatments continued to produce 3-4 s episode durations (Fig. 4Aii) ( $p<0.001$; Kruskal-Wallis one-way ANOVA; pairwise difference $p<0.05$ between 8 -bromo-cGMP and CPTIO using Dunn's method). With an average rhythm frequency at $30^{\circ} \mathrm{C}$ $\sim 21 \mathrm{~Hz}$, independent of treatment, these episode durations would produce effective swim sequences of $63-84$ cycles. At $30^{\circ} \mathrm{C}$ on the decreasing temperature ramp after failure (i.e., during recovery), no swimming could be elicited in the presence of 8-bromocGMP or SNAP and only a few cycles in untreated controls, whereas in the presence of NO/cGMP pathway inhibitors there was sufficient recovery to generate short sequences $(\sim 1 \mathrm{~s})$ (Fig. 
Table 1. Manipulation of the N0/cGMP pathway does not affect the temperature sensitivity of swim cycle frequency

\begin{tabular}{lrlllll}
\hline & & $\begin{array}{l}\text { Regression } \\
\text { slope } \\
\left(\mathrm{Hz} /{ }^{\circ} \mathrm{C}\right)\end{array}$ & & & & \multicolumn{2}{l}{$\begin{array}{l}\text { Regression } \\
\text { intercept } \\
(\mathrm{Hz})\end{array}$} & \\
\cline { 3 - 6 } & $n$ & Mean & SE & & Mean & SE \\
\hline Control & 18 & 0.72 & 0.07 & & -0.34 & 1.50 \\
SNAP & 5 & 0.57 & 0.16 & & 0.46 & 3.53 \\
CGMP & 5 & 0.72 & 0.10 & & 1.05 & 2.33 \\
CPTIO & 7 & 0.74 & 0.09 & & -1.45 & 2.09 \\
L-NAME & 9 & 0.62 & 0.04 & 2.13 & 0.80 \\
ODQ & 7 & 0.74 & 0.06 & -0.69 & 1.20 \\
\hline
\end{tabular}

Pharmacological activation (8-bromo-CGMP and SNAP) and inhibition (CPTIO, L-NAME, ODQ) of the N0/CGMP pathway had no effect relative to control on the slope or the intercept of the linear regression fitted to the relationship between increasing temperature and swim cycle frequency. Average rhythm frequency of sequences with $10-50$ swim cycles (fewer cycles at higher temperatures as episode durations decreased) were calculated at three to five different temperatures during the increasing temperature ramp, and the data were fitted with a linear regression using a least-squares procedure. See Materials and Methods for drug description.

4Aiii) with an increased rhythm frequency $(23-26 \mathrm{~Hz}$; data not shown). There was a significant effect of treatment ( $p=0.001$; Kruskal-Wallis one-way ANOVA), but no pairwise differences were identified (Dunn's method).

Drug treatments had strong effects on the temperature thresholds for failure and recovery of TS swimming. We scored failure when $<5$ swim cycles could be activated by stimulation (Fig. 3 Aii). On recovery, however, the first TS swim episode duration was usually $1 \mathrm{~s}$ (>20 cycles) or more (Fig. $2 \mathrm{~B}$, inset). The mean episode duration $<1 \mathrm{~s}$ for controls in Figure 4 Aiii included some individual durations of zero. Activation of the NO/cGMP pathway decreased the temperature at which swim episodes could no longer be elicited by stimulation of the tail from $31.7 \pm 0.5^{\circ} \mathrm{C}(n=18$, controls) to $28.8 \pm 0.2^{\circ} \mathrm{C}(n=5,8$-bromo-cGMP), whereas inhibition of the pathway increased this temperature to $33.4 \pm 0.5^{\circ} \mathrm{C}(n=$ 7 , ODQ) (Fig. $4 \mathrm{Bi})\left(p<0.001\right.$; ANOVA). Thus, there was a $4.6^{\circ} \mathrm{C}$ difference in failure temperature between minimum (NO/cGMP pathway activation) and maximum (pathway inhibition) values. The measures of recovery temperature and time to recovery are not independent of each other, because the temperature decreased with the same exponential rate profile after turning off the heater. For rapid recoveries, time increased and temperature decreased together (i.e., both measures provide equivalent information on the rate of recovery); however, for recoveries longer than $\sim 180 \mathrm{~s}$, the rate of decrease in temperature was greatly slowed, and the passage of time became a more significant factor. Recovery temperature was $26.4 \pm$ $0.6^{\circ} \mathrm{C}$ in controls, $22.3 \pm 0.5^{\circ} \mathrm{C}$ with 8 -bromo-cGMP and $29.9 \pm$ $0.7^{\circ} \mathrm{C}$ with ODQ to give a maximum difference between treatments of $7.6^{\circ} \mathrm{C}$ (Fig. $\left.4 \mathrm{Bii}\right)(p<0.001$; ANOVA). The time taken to recover was $292 \pm 29 \mathrm{~s}$ in controls, $531 \pm 50 \mathrm{~s}$ with 8-bromo-cGMP, and $190 \pm 14 \mathrm{~s}$ with ODQ to give a maximum difference between treatments of $341 \mathrm{~s}$ or $5-6$ min (Fig. 4 Biii) $(p<0.001$; Kruskal-Wallis one-way ANOVA). In summary, manipulation of the NO/cGMP pathway had marked effects on the temperature dependence of swim motor pattern generation in Xenopus tadpoles.

\section{Discussion}

We examined the contribution of the NO/cGMP pathway to determine the thermosensitivity of the swimming CPG in posthatching Xenopus laevis larvae. Our main conclusion is that the $\mathrm{NO} / \mathrm{cGMP}$ pathway plays a role in tuning the thermosensitivity of the swimming circuit by setting the thresholds for failure and recovery, as well as by modulating the duration of swim episodes. We show that the presence of an NO donor (SNAP) greatly hindered the recovery from hyperthermic failure of the swim circuitry, regardless of whether the motor pattern was activated by electrical stimulation of the tail skin or by superfusion with the glutamate receptor agonist NMDA. This demonstrates that the effects of $\mathrm{NO}$ on recovery from hyperthermia are mediated via actions at the level of the central circuits and not the sensory pathways from the skin to the spinal cord, though the latter may also be affected by NO (Alpert et al., 2007). Using tail-stimulated swimming, we show that activation of the NO/cGMP pathway renders most measures of circuit function more sensitive to hyperthermia, whereas inhibition of the pathway has the opposite effect and reduces their thermosensitivity. The measure that was not noticeably affected was the temperature sensitivity of swim rhythm frequency. We suggest that the functional role of this effect of the NO/cGMP pathway is to modulate excitability and energy consumption, dependent on previous environmental conditions. Thus, increases in abiotic stressors activating the NO/cGMP pathway, such as hyperthermia or hypoxia, would reduce locomotion and hence conserve energy, enabling the organism to cope with these conditions more effectively.

The effects of extreme high temperature on neural processes can be divided into two main types: those that have immediate consequences as a result of the $Q_{10}$ relationships of the rates of neural phenomena such as the opening and closing of ion channels; and those that have a temporal component reflecting an accumulating disturbance such as gradual protein denaturation or the loss of ionic equilibria (Robertson, 2004). The increase in swim cycle frequency with increasing temperature is not surprising, because this is a well established property of CPGs (Walker, 1975; Tryba and Ramirez, 2003) that is due to the reduction of conduction and synaptic delays between elements in the circuit (Robertson, 2004). The profound decrease in swim episode duration with increasing temperature is not as easy to explain. At room temperature, the duration of swim episodes in stage 42 larvae is determined partly by the timing of activation of GABAergic inhibition (Reith and Sillar, 1999), which can prematurely terminate swimming. One possibility is that increased temperature simply speeds up the processes controlling this timing via $Q_{10}$ relationships, i.e., in the same way that the durations of action potentials and synaptic potentials decrease with increasing temperature (Janssen, 1992). Indeed, one of the prominent actions of NO is to decrease swim episode duration by potentiating GABA transmission (McLean and Sillar, 2002), and thus an associated hypothesis is that increased temperature increases the production of NO by increasing the enzymatic activity of NOS and that it is the action of NO at GABAergic synapses that decreases episode duration. In this scenario, it would have to be proposed that the action of $\mathrm{NO}$ to decrease cycle frequency (via potentiation of glycinergic transmission) (McLean and Sillar, 2002) is more than counterbalanced by the direct actions of temperature to increase cycle frequency. Moreover, one would need to propose that any release of NO during the temperature ramp is sufficient to affect episode duration but insufficient to have the dramatic effect on recovery temperature and recovery time that pharmacological activation of the NO/cGMP has. These difficulties, and the observation that manipulation of the NO/cGMP pathway had no effect on temperature sensitivity of the rhythm frequency, lead us to believe that most of the temperature-induced shortening of swim episodes is not mediated via NO.

Our experiments did not address the mechanisms underlying hyperthermic failure and subsequent recovery of motor pattern generation in the spinal cord. Many different processes are likely to be implicated, including the failure to generate action potentials, the increased likelihood of conduction failure at axonal regions of low safety factor, and the failure of synaptic transmission (Janssen, 1992; Robertson, 2004). An important common feature of all of these possibilities is a dysregulation of ion homeostasis or conductance. Ac- 
tion potential failure is predicted by the Hodgkin-Huxley equations as $\mathrm{K}^{+}$currents overwhelm $\mathrm{Na}^{+}$currents at high temperature (Chapman, 1967). Synaptic failure at the Drosophila neuromuscular junction results from a loss of the ability to regulate intracellular $\mathrm{Ca}^{2+}$ concentrations (Klose et al., 2008). Given these precedents and the time dependence of recovery of the tadpole swim CPG, we believe it to be a reasonable supposition that hyperthermic failure and recovery in this system are closely related to loss and restoration of appropriate ion gradients.

NO has many and various important roles to play in neural function and dysfunction (Guix et al., 2005; Garthwaite, 2008). The modulatory effects of NO on a variety of neuronal circuits across different phyla have been described. NO affects rhythmic motor activity in jellyfish swimming (Moroz et al., 2004), snail feeding (Kobayashi et al., 2000), and cardiac activity (Taylor et al., 2003), crab stomatogastric activity (Scholz et al., 2001; Stein et al., 2005), locust oviposition (Newland and Yates, 2007), and mouthpart movements (Rast, 2001), frog respiration (Hedrick and Morales, 1999), tadpole swimming (McLean and Sillar, 2000), lamprey swimming (Kyriakatos and El Manira, 2007), and mammalian respiration (Pierrefiche et al., 2007; Reeves et al., 2008). The mechanisms NO uses to exert its effects are less well known, with a notable exception being in the tadpole spinal cord (McLean and Sillar, 2002, 2004). Nevertheless, it remains difficult to explain the effects of $\mathrm{NO}$ on hyperthermic failure and recovery through its described facilitatory effects on glycinergic and GABAergic neurotransmission, and better understanding of the mechanisms will require further investigation.

Behavioral flexibility in the face of highly variable environmental conditions is considered to be a primary role for neuromodulation of CPGs (Dickinson, 2006). Despite this awareness, and the often very detailed knowledge of the cellular and synaptic mechanisms underlying neuromodulator action, the environmental contexts requiring motor pattern changes are less well known. This may be simply because the appropriate contexts have not been presented to the animal or preparation. Thus, we know that, at these early stages of Xenopus development, NO acts as a brake on swimming, but we do not know the conditions appropriate for this. NO is known to be released by, and mediate responses to, cellular stressors such as hypoxia (Wingrove and O'Farrell, 1999; Reeves et al., 2008) and hyperthermia (Armstrong et al., 2009), and we can interpret our findings as NO reducing the probability of swimming to conserve energy during exposure to more stressful environments. NO makes the swim CPG output less intense and causes it to cease functioning at a
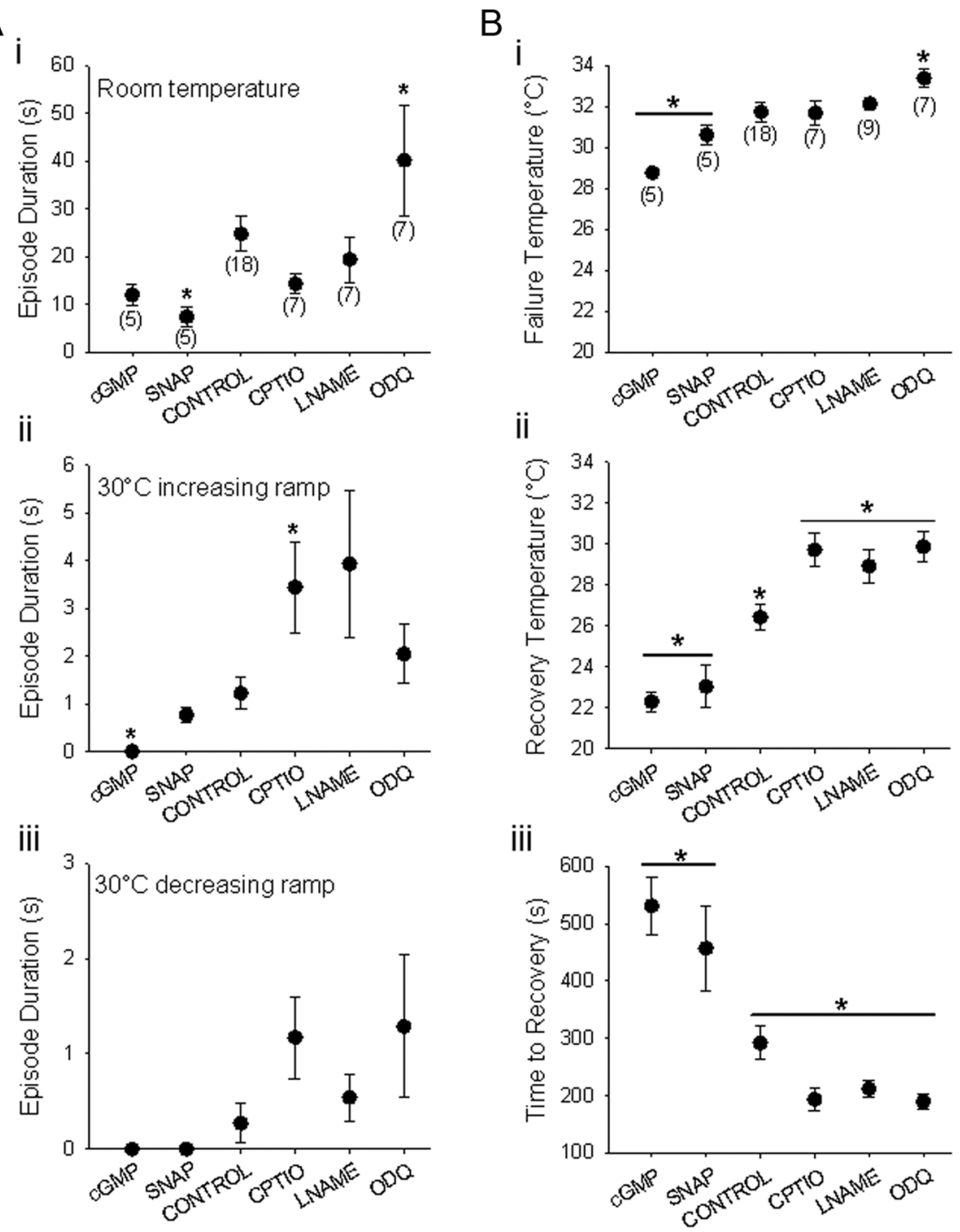

Figure 4. Manipulation of the NO/CGMP pathway affects TS-evoked swim episodes during hyperthermia. $\boldsymbol{A}$, Effects on episode duration. Ai, Activation of the N0/CGMP pathway with 8-bromo-cGMP (CGMP) and SNAP decreased episode duration at room temperature, whereas downregulation of the pathway with CPTIO, L-NAME, and ODQ had the opposite effect. Aii, At $30^{\circ} \mathrm{C}$ during the increasing temperature ramp, the effects of the drugs were exacerbated. Aiii, At $30^{\circ} \mathrm{C}$ during the decreasing temperature ramp after hyperthermic failure, the effects of the drugs were exacerbated. Note that no swim episodes could be evoked at this time in the presence of 8-bromo-cGMP or SNAP. Asterisks indicate significant difference between these data points ( $p<0.05$; Kruskal-Wallis one-way ANOVAfollowed by Dunn's method for pairwise comparisons). $\boldsymbol{B}$, Effects on hyperthermic failure and recovery of swim motor patterns. Bi, Activation of the NO/cGMP pathway with 8-bromo-CGMP and SNAP decreased the failure temperature, whereas downregulation of the pathway with CPTIO, L-NAME, and ODQ had the opposite effect. Bii, Activation of the NO/CGMP pathway decreased the recovery temperature, whereas downregulation of the pathway had the opposite effect. Biii, Activation of the N0/cGMP pathway increased the time taken to recover from hyperthermic failure. Downregulation of the pathway did not significantly decrease the recovery time compared with controls. Asterisks indicate significant difference between these data points ( $p<0.05$; ANOVA followed by Holm-Sidak for pairwise comparisons), and a bar above symbols indicates no significant difference between these data points. See Materials and Methods for drug description. Data points indicate means $\pm \mathrm{SE}$, and sample size is indicated parenthetically under the symbol.

lower temperature. These are modifications that would conserve energy. Moreover, the modulation of spinal circuitry by NO is long lasting (Kyriakatos and El Manira, 2007), befitting a response to a changing environment.

The control animals in our study were variable, and their responses to hyperthermia fell along a continuum between those of preparations treated with activators of NO/cGMP and those treated with inhibitors. For example, we found that the tadpoles from the breeding colony had markedly variable swim durations (several seconds to several tens of minutes) before any manipulations (see supplemental information and supplemental Fig. 
S1, available at www.jneurosci.org as supplemental material). Interestingly, the duration of swim episodes also correlates with rearing temperature (see supplemental information and supplemental Fig. S2, available at www.jneurosci.org as supplemental material). Cool-reared individuals swim for longer on average than those reared under warm conditions. Swim duration is determined at least partly by levels of NO (McLean and Sillar, 2000). We interpret the evident variability in swim duration as reflecting variable conditions in the rearing chambers (e.g., temperature, oxygenation, crowding, lighting, etc. that were not precisely controlled) and that short swim durations indicate previous experience of a more stressful nature causing increased levels of NO. Another source of variability, which may affect the NO systems, is the dissection before recording which could, at least in principle, lead to variable levels of iNOS activation and hence alter the production of $\mathrm{NO}$ and episode duration. It is clear that NO has a continuous role to play, because inhibition of the NO/cGMP pathway has effects without previous pharmacological activation (this paper) (McLean and Sillar, 2000).

We conclude that NO modifies the thermosensitivity of the swim circuit in the spinal cord of Xenopus tadpoles, making it more sensitive to hyperthermia. Thus, we describe here a possible functional role for the well characterized effect of $\mathrm{NO}$ on the swimming CPG in tadpoles and propose that the NO/cGMP pathway may be involved more generally in tuning the CNS and organismal responses to the abiotic environment.

\section{References}

Alpert MH, Zhang H, Molinari M, Heitler WJ, Sillar KT (2007) Nitric oxide modulation of the electrically excitable skin of Xenopus laevis frog tadpoles. J Exp Biol 210:3910-3918.

Armstrong GA, Shoemaker KL, Money TG, Robertson RM (2006) Octopamine mediates thermal preconditioning of the locust ventilatory central pattern generator via a cAMP/protein kinase A signaling pathway. J Neurosci 26:12118-12126.

Armstrong GA, Rodgers CI, Money TG, Robertson RM (2009) Suppression of spreading depression-like events in locusts by inhibition of the $\mathrm{NO} /$ cGMP/PKG pathway. J Neurosci 29:8225-8235.

Arshavsky YuI, Orlovsky GN, Panchin YuV, Roberts A, Soffe SR (1993) Neuronal control of swimming locomotion: analysis of the pteropod mollusc Clione and embryos of the amphibian Xenopus. Trends Neurosci 16:227-233.

Behan-Martin MK, Jones GR, Bowler K, Cossins AR (1993) A near perfect temperature adaptation of bilayer order in vertebrate brain membranes. Biochim Biophys Acta 1151:216-222.

Chapman RA (1967) Dependence on temperature of the conduction velocity of the action potential of the squid giant axon. Nature 213:1143-1144.

Dale N, Kuenzi FM (1997) Ion channels and the control of swimming in the Xenopus embryo. Prog Neurobiol 53:729-756.

Dale N, Roberts A (1984) Excitatory amino acid receptors in Xenopus embryo spinal cord and their role in the activation of swimming. J Physiol 348:527-543.

Dawson-Scully K, Armstrong GA, Kent C, Robertson RM, Sokolowski MB (2007) Natural variation in the thermotolerance of neural function and behavior due to a cGMP-dependent protein kinase. PLoS ONE 2:e773.

Dickinson PS (2006) Neuromodulation of central pattern generators in invertebrates and vertebrates. Curr Opin Neurobiol 16:604-614.

Garthwaite J (2008) Concepts of neural nitric oxide-mediated transmission. Eur J Neurosci 27:2783-2802.

Guix FX, Uribesalgo I, Coma M, Muñoz FJ (2005) The physiology and pathophysiology of nitric oxide in the brain. Prog Neurobiol 76:126-152.

Hedrick MS, Morales RD (1999) Nitric oxide as a modulator of central respiratory rhythm in the isolated brainstem of the bullfrog (Rana catesbeiana). Comp Biochem Physiol A Mol Integr Physiol 124:243-251.

Janssen R (1992) Thermal influences on nervous system function. Neurosci Biobehav Rev 16:399-413.

Johnston IA, Temple GK (2002) Thermal plasticity of skeletal muscle phenotype in ectothermic vertebrates and its significance for locomotory behaviour. J Exp Biol 205:2305-2322.
Kelty JD, Noseworthy PA, Feder ME, Robertson RM, Ramirez JM (2002) Thermal preconditioning and heat-shock protein 72 preserve synaptic transmission during thermal stress. J Neurosci 22:RC193.

Klose MK, Atwood HL, Robertson RM (2008) Hyperthermic preconditioning of presynaptic calcium regulation in Drosophila. J Neurophysiol 99:2420-2430.

Kobayashi S, Ogawa H, Fujito Y, Ito E (2000) Nitric oxide suppresses fictive feeding response in Lymnaea stagnalis. Neurosci Lett 285:209-212.

Kyriakatos A, El Manira A (2007) Long-term plasticity of the spinal locomotor circuitry mediated by endocannabinoid and nitric oxide signaling. J Neurosci 27:12664-12674.

McLean DL, Sillar KT (2000) The distribution of NADPH-diaphoraselabelled interneurons and the role of nitric oxide in the swimming system of Xenopus laevis larvae. J Exp Biol 203:705-713.

McLean DL, Sillar KT (2002) Nitric oxide selectively tunes inhibitory synapses to modulate vertebrate locomotion. J Neurosci 22:4175-4184.

McLean DL, Sillar KT (2004) Metamodulation of a spinal locomotor network by nitric oxide. J Neurosci 24:9561-9571.

Moroz LL, Meech RW, Sweedler JV, Mackie GO (2004) Nitric oxide regulates swimming in the jellyfish Aglantha digitale. J Comp Neurol 471:26-36.

Newland PL, Yates P (2007) Nitrergic modulation of an oviposition digging rhythm in locusts. J Exp Biol 210:4448-4456.

Nieuwkoop PD, Faber J (1956) Normal tables for Xenopus laevis. Amsterdam: Daubin.

Pierrefiche O, Abdala AP, Paton JF (2007) Nitric oxide and respiratory rhythm in mammals: a new modulator of phase transition? Biochem Soc Trans 35:1258-1263.

Rast GF (2001) Nitric oxide induces centrally generated motor patterns in the locust suboesophageal ganglion. J Exp Biol 204:3789-3801.

Reeves SR, Simakajornboon N, Gozal D (2008) The role of nitric oxide in the neural control of breathing. Respir Physiol Neurobiol 164:143-150.

Reith CA, Sillar KT (1999) Development and role of GABA(A) receptormediated synaptic potentials during swimming in postembryonic Xenopus laevis tadpoles. J Neurophysiol 82:3175-3187.

Robertson RM (2004) Thermal stress and neural function: adaptive mechanisms in insect model systems. J Therm Biol 29:351-358.

Robertson RM, Xu H, Shoemaker KL, Dawson-Scully K (1996) Exposure to heat shock affects thermosensitivity of the locust flight system. J Neurobiol 29:367-383.

Rodgers CI, Armstrong GA, Shoemaker KL, LaBrie JD, Moyes CD, Robertson RM (2007) Stress preconditioning of spreading depression in the locust CNS. PLoS ONE 2:e1366.

Scholz NL, de Vente J, Truman JW, Graubard K (2001) Neural network partitioning by NO and cGMP. J Neurosci 21:1610-1618.

Sillar KT, Robertson RM (2009) Thermal activation of escape swimming in post-hatching Xenopus laevis frog larvae. J Exp Biol 212:2356-2364.

Sillar KT, Combes D, Ramanathan S, Molinari M, Simmers J (2008) Neuromodulation and developmental plasticity in the locomotor system of anuran amphibians during metamorphosis. Brain Res Rev 57:94-102.

Stein W, Eberle CC, Hedrich UB (2005) Motor pattern selection by nitric oxide in the stomatogastric nervous system of the crab. Eur J Neurosci 21:2767-2781.

Taylor BE, Harris MB, Burk M, Smyth K, Lukowiak K, Remmers JE (2003) Nitric oxide mediates metabolism as well as respiratory and cardiac responses to hypoxia in the snail Lymnaea stagnalis. J Exp Zool A Comp Exp Biol 295:37-46.

Tryba AK, Ramirez JM (2003) Response of the respiratory network of mice to hyperthermia. J Neurophysiol 89:2975-2983.

Walker TJ (1975) Effects of temperature on rates in Poikilotherm nervous systems-evidence from calling songs of meadow katydids (OrthopteraTettigoniidae-Orchelimum) and reanalysis of published data. J Comp Physiol 101:57-69.

Wilson RS, James RS, Johnston IA (2000) Thermal acclimation of locomotor performance in tadpoles and adults of the aquatic frog Xenopus laevis. J Comp Physiol B 170:117-124.

Wingrove JA, O'Farrell PH (1999) Nitric oxide contributes to behavioral, cellular, and developmental responses to low oxygen in Drosophila. Cell 98:105-114.

Xiao C, Mileva-Seitz V, Seroude L, Robertson RM (2007) Targeting HSP70 to motoneurons protects locomotor activity from hyperthermia in Drosophila. Dev Neurobiol 67:438-455. 